\author{
Oscar \\ Alatriste Guzmán \\ CEPE-UNAM
}

\section{XOCHIMILCO PREHISPÁNICO.}

Localizada al sureste de la ciudad de México, Xochimilco, que en nahuatl significa "en la sementera de flores", es una región que se ha caracterizado por ser lacustre y escenario de una historia rica en procesos y acontecimientos sociales desde tiempos remotos, de los cuales sus restos arqueológicos, monumentos coloniales y porfiristas, su extensa red de canales y chinampas, sus fiestas $\mathrm{y}$ tradiciones, son fiel testimonio.

Bañado de agua dulce por varios ríos y 14 manantiales, el lago de Xochimilco, uno de los cinco que conformaban la cuenca de México, desde tiempos remotos proporcionó una amplia variedad de recursos alimenticios y condiciones materiales favorables para practicar la agricultura, a quienes se establecieron ahí desde tiempos lejanos.

La región comenzó a ser pobladada desde tiempos prehistóricos. A partir del 1500 a. de C. estuvo bajo la influencia, primero de Cuicuilco, después de Teotihuacán y, finalmente, según diversas fuentes históricas, de los "Xochimilcas", primera de las siete tribus nahuatlacas en 1legar a la cuenca de México, hecho que tuvo lugar a principios del siglo x d. de C. ${ }^{1}$

Habiendo pasado previamente por Tula, la familia Xochimilca 1legó a rodear el valle de México hasta la región del lago, donde se fusionó con los pocos nativos que aún vivían. Durante los primeros doscientos años extendieron los límites de su influencia y se transformaron en un pueblo poderoso.

Establecieron su capital originalmente en Cuahilama (frente a Santa Cruz Acalpixcan, en 1196 d. de C. y posteriormente en Tlilan (hoy parroquia de Xochimilco) en 1352. ${ }^{2}$ Aquí, conformaron una organización económica, social, política y religiosa que les permitió crear una iden-
1 José Farías Galindo, Xochimilco en el tiempo. México, Departamento del Distrito Federal, 1984, p. 14; Shand Harmon Stringham, "Xochimilco la subordinación imperial desde tiempos prehispánicos hasta 1600", en tesis de maestría en Historia Latinoamericana, CEPEUNAM, 1981, pp. 13-16.

2 José Farías Galindo, op. cit., p. 15. 


3 Araceli Peralta Flores y
Jorge Rojas Ramírez,
Xochimilco
y sus monumentos
históricos. México, Instituto
Nacional de Antropología e
Historia,
1991, p. 21.
4 Son muchos los autores que
describen las característi-
cas de las chinampas.
Información precisa sobre el
pasado y presente de esa
técnica agrícola la
encontramos en el reporte
sobre las conclusiones y
recomendaciones a las que
llegaron los participantes de
la conferencia internacional
"Pasado, Presente y Futuro
de las Chinampas",
efectuado en la ciudad de
México los días 23,24 y 25
de abril de 1990, Vid. Juan
Jiménez Osario, et. al.,
Pasado, Presente y Futuro
delas Chinampas.
Riverside, Universidad de
California, en Riverside
[Proyecto] Sostenibilidad
Maya, 1990.
Ibidem.

3 Araceli Peralta Flores $y$ Jorge Rojas Ramírez, Xochimilco y sus monumentos históricos. México, Instituto Nacional de Antropología e Historia,

1991, p. 21

describen las ca cas de las chinampas. Información precisa sobre el pasado y presente de esa técnica agrícola la encontramos en el reporte sobre las conclusiones $y$ recomendaciones a las que llegaron los participantes de la conferencia internacional "Pasado, Presente y Futuro de las Chinampas", efectuado en la ciudad de México los días 23, 24 y 25 de abril de 1990, Vid. Juan Jiménez Osario, et. al., Pasado, Presente y Futuro Riverside, Universidad de California, en Riverside [Proyecto] Sostenibilidad 5 Ibidem. tidad de grupo y una cultura propia.

Con el correr del tiempo Xochimilco se formó en una ciudad dividida en tres parcialidades, que comprendían varios barrios y pueblos cada una; Tepetenchi (la orilla de las montañas donde había pueblos y pequeños conglomerados humanos), Tecpan (Centro de la ciudad, barrios artesanos, zona comercial y de gobierno) y Olac (alrededores de la ciudad, donde había casas dispersas ocupadas por indios chinamperos). ${ }^{3}$

La base de la economía de los xochimilcas fue la agricultura, la que desarrollaron en terrazas a lo largo de las laderas de los cerros y, sobre todo, por medio de las "chinampas" (cerco de cañas): empalizada o estacada que se asentaba sobre el fondo del lago, la cual se rellenaba con piedra, lodo del fondo del lago, plantas acuáticas y otros materiales; sus orillas se protegían con entretejidos de diversos materiales vegetales. ${ }^{4}$

Las chinampas permitieron una agricultura independiente del régimen de 1luvias en una área de aproximadamente 20000 has. Permitieron el cultivo de maíz, muchos tipos de hortalizas y un número considerado de flores, junto con algunos árboles frutales o típicos como el "ahuejote" cuyas raíces ayudan a fijar las chinampas y le dan fisonomía propia al paisaje.

Después de ser conquistados por las fuerzas de 1a "Triple Alianza" en 1453, los xochimilcas perdieron la mayor parte de su territorio en un repartimiento de sus tierras entre los mexicas y tezcocanos. Por orden de los mexicas se emprendió el desagüe de los pantanos de Xochimilco y se construyeron nuevas chinampas amontonando el lodo del fondo del lago en largas franjas que formaban isletas angostas separadas por canales. Con el tiempo, ellago de Xochimilco fue cubierto por una red sistemática de chinampas, canales y lagunas. Se calcula que la región de Xochimilco y Chalco proveían de entre la mitad y las dos terceras partes de comestibles que requería la ciudad de Tenochtilán. ${ }^{5}$

Además de trabajar las chinampas, los xochimilcas eran muy activos en otros aspectos de la vida económica del estado azteca. Xochimilco era un importante centro comercial y artesanal; era un paso en la 1legada al valle de productos de la tierra caliente. Sus comerciantes te- 
nían gran actividad en el comercio del estado azteca, tanto en los mercados locales, como en lugares lejanos. En el Centro de Xochimilco o Tecpan realizaban importantes actividades comerciales. Además fueron importantes artesanos, en especial grandes lapidarios.

La sociedad xochimilca estaba compuesta por un sector de nobles, en los que se encontraban los gobernantes, sacerdotes y soldados destacados. Sus hijos asistían al Calmecac o escuela para nobles, donde aprendían la escritura, los calendarios, la astronomía, a leer los códices, etc. Enseguida se ubicaba un sector de comerciantes y artesanos, localizados en distintos barrios de la ciudad y por último el gran sector de indios. Como sucedía con el resto de los pueblos mesoamericanos, 1os xochimilcas eran muy religiosos, practicaron un gran ceremonialismo y eran politeístas chinamperos y pescadores.

Contaban con 16 dioses tutelares entre los que se pueden mencionar a Centeotl (dios de las sementeras y el maíz), a Xochiquetzalli (diosa de las flores), a Cihuacoatl (diosa de la fecundidad) y a Anúmitl (dios de las chinampas y los chinamperos). ${ }^{6}$

Sus sacerdotes fueron grandes astrónomos, 1levaron un recuento preciso de los días en sus calendarios civil (365 días) y religioso (260 días). Esta información era determinante para saber con exactitud las fechas cuando se debían celebrar las conmemoraciones y ceremonias.

Testimonios de la grandeza de este pueblo los podemos admirar en la zona arqueológica de Cuahilama (restos de estructuras piramidales y bellos petroglifos) y en el museo Arqueológico de Xochimilco.

A partir del siglo XiıI d. de C. la organización política de los xochimilcas adopta la forma de señorío. Xochimilco estuvo integrado por tres gobiernos con tres tlatoanis o señores, uno para la parcialidad de Olac, otro para la de Tepetenchi y otro más para la de Tecpan. Parece ser que el señor de Tepetenchi era el más importante. ${ }^{7}$

Estos señores tuvieron que hacer frente a diversos conflictos con los pueblos circunvecinos, primero defendiendo su territorio exitosamente contra los tlahuicas, posteriormente contra Culhuacán, Azcapotzalco y la Triple Alianza ante quienes sufren sendas derrotas. Bajo la hegemonía de la última, la zona de influencia de Xochi-
6 Farías, op. cit., pp. 15-17.

7 Juan Manuel Perez-Zevallos, "Organización del señorío Xochimilca", en Rebeca Ramos, Ludka de Gortari y Manuel Pérez Zevallos, Xochimilco en el siglo XVI. México, Centro de Investigaciones $y$ Estudios Superiores en Antropología Social-INAH, 1981, pp. 107-118. 
8 Farias, op. cit., pp. 25-32; Peralta Flores y Rojas Ramírez, op. cit., pp. 22-23.

9 Pérez-Zevallos, op. cit., pp. 118-121. milco se redujo a la orilla del lago, entre el Pedregal y el extremo de Tláhuac. Los xochimilcas fueron obligados entonces a participar con su trabajo en la construcción de la calzada de Iztapalapa y a intervenir con sus armas en las campañas de expansión imperialista. Contribuyeron asimismo a repoblar las localidades que iban arrasando los aztecas y aportaron mano de obra y materiales para erigir el Templo de Huitzilopochtli en tiempos de Moctezuma Ilhuicamina y el acueducto de Coyoacán a México en la época de Ahuizotl. ${ }^{8}$

Durante la conquista de Tenochtitlán por los españoles y sus aliados, los xochimilcas combatieron a Hernán Cortés, derrotándolo en la Noria y posteriormente cayendo ante el rápido y sorpresivo ataque que mandó el conquistador durante el sitio de Tenochtitlán.

Por ser vasallos de los aztecas antes de consumarse la conquista los xochimilcas fueron llamados a combatir en Tenochtitlán contra los españoles, sin embargo, al parecer, los de Xochimilco comenzaron a combatir contra los mexicas, por lo que la mayoría fueron ajusticiados por éstos. Una versión dice que los xochimilcas auxiliaron a los españoles y que se pusieron a la orden de ellos. ${ }^{9}$

\section{XOCHIMILCO DURANTE LA ÉPOCA VIRREINAL}

Después de la rendición de Tenochtitlán, los xochimilcas se adaptaron rápida y eficazmente a las nuevas condiciones económicas, políticas y culturales de la Colonia, sin ser asimilados y absorbidos. Mantuvieron el carácter indígena del pueblo a pesar de su participación activa en la economía, la política y la vida religiosa impuesta por los españoles. Recuperaron sus tierras y áreas agrícolas tradicionales, usurpadas por los mexicas. Continuaron cultivando sus chinampas, este sistema prehispánico de agricultura intensiva quedó como una especialidad indígena que no le interesó a los españoles, por lo que los xochimilcas lograron con éxito mantener el predominio indígena de la región. Cuando les fue exigido que pagaran su tributo en maíz y dinero, la economía monetaria fue rápidamente asimilada por los xochimilcas; los comerciantes viajaban por casi toda la Nueva España vendiendo productos españoles e indígenas bajo estas nuevas 
condiciones, en particular destacó un intenso tráfico comercial con la ciudad de México, a la cual se transportaban, además de los productos agrícolas de Xochimilco, mercancías provenientes de tierra caliente, tales como madera, cera de Campeche, azúcar, vino, arroz, trigo, etc. ${ }^{10}$

Por otro lado, los xochimilcas siguieron muy activos en la producción de artesanías y manufacturas. No sólo destacaron en las empresas de origen prehispánico, sino también en los nuevos oficios introducidos por los españoles, de los primeros destacaron los producidos por los artesanos de distintos barrios así por ejemplo, entre otros, los carpinteros y escultores de Tepetenchi, y los herreros y alfareros de Tecpan; ${ }^{11}$ de los segundos se puede mencionar el cultivo de aceitunas en pueblos tales como Tulyehualco, San Gregorio e Ixtayopan. ${ }^{12}$

Aunado a lo anterior y a pesar del predominio indígena en la región, los españoles también tuvieron algunas empresas económicas, tales como los cuatro obrajes de lana existentes a principios del siglo XVII y algunas pequeñas empresas ganaderas y agrícolas. El ganado existente era de establo debido a las limitaciones topográficas: pocos pastizales. Cuando la ganadería tuvo un desarrollo más favorable, se estableció un matadero donde para 1576 se llegaron a sacrificar dos mil quinientos novillos. ${ }^{13}$

Después de ser encomienda de Pedro Alvarado, en 1541 Xochimilco pasó a manos de la Corona como corregimiento, por lo que se nombró a un corregidor español para su administración, a su vez, éste confirmó a los caciques indígenas de las antiguas parcialidades Tecpan, Tepetenchi y Olac (ahora denominados barrios) que conformaban la encomienda en gobernadores, cada uno de los cuales era ayudado por tres o cuatro indios principales. ${ }^{14}$ Asimismo, organizó el cabildo de Xochimilco con oficiales de la nobleza indígena, cuando en 1559 esta población obtiene el título de "Noble Ciudad" y su escudo de armas, mismos que conservó hasta $1779 .{ }^{15}$

El corregimiento llegó a ser una fuerza estabilizadora en Xochimilco, incorporó dentro de su jurisdicción a todas las tierras xochimilcas tradicionales y contribuyó a preservar intacto el pueblo xochimilca como una entidad. A partir de 1787 Xochimilco fue subdelegación de la intendencia de México. ${ }^{16}$
10 Charles Gibson, Los aztecas bajo el dominio español (15191810). México, Siglo XXI, 1978, pp. 368-369; Peralta Flores y Rojas Ramírez, op. cit., $\mathrm{p}$.

11 Ibidem.

12 Peralta Flores, Rojas Ramírez, op. cit., p. 36.

13 Gibson, op. cit., p. 355.

14 Para mayor información sobre los primeros gobernadores Xochimilcas durante el siglo XVI, vid. Pedro Carrasco, "Los señores de Xochimilco en 1548", en Tlalocan, vol. 7, 1977, pp. 229-265.

15 Farías, op. cit., pp. 103-107.

16 Peter Gerhard, Geografía histórica de la Nueva España. 1519-1821. México, UNAM$\mathrm{IIH}, 1986$, p. 251. 
17 Gibson, op. cit., p. 444.

$18 \mathrm{Al}$ aparecer la información sobre los barrios de Xochimilco que presenta Farías en su Xochimilco en el tiempo, pp. 110-1I5, corresponden a la realidad de Tecpan.

19 Para una descripción breve de los pueblos y sus capillas vid. Farías, op, cit., pp. 115$117,119-127$

20 Gerhard, op. cit., p. 253.
Al parecer las tres parcialidades en que se dividía Xochimilco comprendían cada una tanto pueblos como barrios. Se dividieron por oficios y especialidades así como por la importancia de sus capillas; en cada una de estas últimas se construyó una plazuela que 1leva generalmente el nombre del patrón local.

En términos generales, durante la colonia, entre pueblos y barrios, Tepetenchi, "en la orilla de los pequeños cerros", comprendía las poblaciones que estaban en los cerros desde el Ajusco hasta Tlacotenco (hacia 1540 la estancia de San Agustín Tlalpan pasó a formar parte de la jurisdicción del pueblo de Coyoacán $)^{17}$ y algunas haciendas y ranchos (destacaban la de San Juan de Dios Coapa y San Antonio Coapa).

Tecpan,| "lugar del palacio", estaba conformada por sus antiguos barrios de oficios y especialidades como el de San Pedro (de herreros); el de San Antonio (de paneleros y ceramistas); San Marcos (de piedreros y ceramistas en incensarios y braceros); San Juan (de floricultores); La Concepción (de escultores); La Asención (de cesteros y Chiquihueteros) y San Francisco Caltongo (de cesteros y carriceros). A finales de la época Colonial contaba ya con trece barrios (Santa Crucita, Xaltocan, Belem, El Rosario, San Cristóbal y la Santísima Trinidad). ${ }^{18}$

Por su parte Olac, "en lo que rodea el agua", abarcaba entre otros pueblos: San Lorenzo Atemoya, San Andrés Ahuayucan, San Francisco Tlalnepantla, Santa Cecilia Tepetlapa, Santiago Tepalcatlalpan, Santiago Tulyehualco, Santa María Tepepan (había pertenecido al Marquesado del Valle de Oaxaca), Santa Cruz Xochitepec (fue aldea de Tepepan), San Mateo Xalpa, San Lucas Xochimanca, San Luis Tlaxialtemalco, San Gregorio Atlapulco, Santa Cruz Acalpixcan y Nativitas (ahora Zacapan). ${ }^{19}$

Hasta el siglo XVII Milpa Alta fue parte del corregimiento de Xochimilco y en particular de la parcialidad de Olac, y por ende los pueblos que estaban sujetos a ella, a saber: San Bartolomé, San Francisco, San Jerónimo, San Antonio Tecómitl, Tepepan, Iztayopan, Mixquic, San Bartolo Tlajomolco, San Pablo Oztotepec, San Pedro Atocpan, San Salvador Cuauhtenco, Tláhuac, Topilejo y Xicalco. ${ }^{20}$ 
Cabe señalar que tanto en los pueblos como en los barrios de esta parcialidad, al igual que en la de Tecpan, se construyeron capillas y ermitas de singular belleza e interés.

A ese extenso territorio se le agregaba el correspondiente a cinco haciendas (la de Jorge Olmedo, San Juan de Dios, Buena Vista, Tzomolco o la Noria y Buenaventura) y nueve ranchos (Coatectlan, Moyocalco, Ojo de Agua, Tepezoyucan, La Venta, El Guarda, Santa Marta, Quetzalapa y Xaltocan). ${ }^{21}$

Durante el periodo colonial los habitantes de Xochimilco contaron con condiciones favorables para su desarrollo socioeconómico y cultural, sobre todo las áreas comprendidas en las parcialidades de Olac y Tecpan; la primera por ser región de producción agrícola-chinampera que continuó abasteciendo de legumbres, frutos y verduras a la ciudad de México, y la segunda por haberse comenzado ahí la traza de la ciudad y con ello el lugar de residencia de los españoles. Se creó una gran plaza rectangular frente al atrio de San Bernardino de Siena, a su alrededor se trazaron las calles principales de la ciudad. Se construyeron otros edificios religiosos, públicos y civiles, esto cambió la fisonomía de lo que fue el centro cívico-ceremonial prehispánico. Los barrios conservaron en gran parte su estructura socioeconómica interna, pero adquirieron un matiz diferente al construirse capillas en cada uno y al substituirse sus nombres prehispánicos por cristianos. ${ }^{22}$

Por su parte, parece que las poblaciones comprendidas en Tepetenchi, ubicada en el área de cerros, no manifestó un crecimiento demográfico. Después de cuarenta años de continua disminución de la población nativa, en 1564 había más de 10000 tributarios indígenas; el número disminuyó durante el siglo XVII. El censo de 1778 da un total de 18000 personas en el corregimiento, que representan quizá 4000 tributarios. En 1801 había 4282 indios tributarios. Al final del periodo colonial (1791) ya residían en Xochimilco 1329 españoles, 578 mestizos y 204 mulatos. ${ }^{23}$ Xochimilco era predominantemente indígena.

Algunos nobles xochimilcas lograron integrarse a la sociedad colonial española. Los principales nobles xochimilcas recibieron favores y privilegios especiales a cambio de su cooperación con las autoridades españolas.

21 Farías, op. cit., p. 109 22 Peralta Flores y Rojas Ramírez, op. cit., p. 46. 23 Gerhard, op. cit., p. 253. 
24 Para un estudio en detalle sobre la conquista espiritual de Xochimilco, vid. Stringham, op. cit., pp. 87-147.

25 Gerhard, op. cit., p. 2502.

26 Existen varias descripciones y estudios sobre este conjunto arquitectónico, Vid. Farías, op. cit., pp. 87-99; Stringham, op. cit., pp. 245265; Francisco José Belgodere Brito, "El retablo de San Bernardino de Siena en Xochimilco", en Anales del Instituto de Investigaciones Estéticas. México, IIE-UNAM, 1969; Mónica Herrería de la Fuente, "El retablo de la Iglesia de Xochimilco". México, 1997. Tesis de licenciatura en Conservación y Restauración de Bienes Muebles, Escuela Nacional de Restauración Conservación y Museografía.
Aunque éstos fueron disminuyendo a fines del siglo XVI, la estratificación social indígena prehispánica se mantuvo durante el periodo colonial.

Como sucedió en el resto del territorio mexicano, inmediatamente después de la conquista militar, Xochimilco fue objeto de una conquista espiritual. La presencia de frailes franciscanos en la región fue muy temprana: Fray Martín de Valencia, Francisco de Soto, Fray Toribio de Benavente (Motolinía) y Fray Andrés de Olmos entre otros franciscanos comenzaron a llegar a Xochimilco desde 1524.

Fundaron la Iglesia y Convento de San Bernardino de Siena, el Hospital de la Concepción y la primera Eucuela de Teología, Arte y Oficios. ${ }^{24}$ En 1560 establecieron otra casa en Asunción Milpa Alta. Si bien éstas fueron las únicas parroquias que sobrevivieron como tales, había asistencia o vicarías franciscanas en San Antonio Tecomitl (1581), San Gregorio Atlacpulco (1600), San Pedro Actopan (1603) y Visitación Santa María Tepepan (1646). Milpa Alta fue secularizada en 1772 y Xochimilco en $1786 . .^{25}$

La conversión de los xochimilcas al cristianismo fue relativamente rápida, ellos mismos de una forma voluntaria destruyeron sus ídolos en presencia de los misioneros. Fue evidente su evangelización por la responsabilidad demostrada al dedicarse a la construcción de las iglesias y conventos de Xochimilco y los pueblos.

En la actualidad podemos admirar la belleza de muchos de estos templos que han sido restaurados en diversas ocasiones. La construcción más importante por su antigüedad, magnitud, y estilos artísticos es la dedicada al ya mencionado San Bernardino de Siena y su convento, ${ }^{26}$ cuya construcción se inició en 1535 y se concluyó en 1590 (el convento y claustro fueron terminados en 1612). Es de una nave sostenida por grandes contrafuertes. Es de estilo monástico militar, con almenas, botareles y gruesos muros. Es notable la portada que adorna la puerta lateral (llamada porciúncula), cuyo estilo plateresco es de tipo grecolatino con influencias góticas e indígenas. En el interior del convento hay influencia románica y mudéjar. Tiene un atrio de grandes dimensiones, en el que se experimenta la sensación de paz y armonía, de estar en un espacio terreno divinizado. 
En su interior existen retablos de estilo plateresco, barroco, churrigueresco y mudéjar. El retablo mayor, verdadera joya de arte renacentista, está dorado de oro de 24 quilates y conjuga escultura y pintura; muestra la historia del cristianismo con los momentos más importantes de la vida de Cristo y algunas representaciones de los orígenes de la Iglesia.

Más templos de interés donde se puede apreciar elementos renacentistas, barrocos y neoclásicos son, entre otros, la Capilla del Rosario, que data de 1796; la iglesia y convento de Santa María Tepepan, de 1599; la capilla de Nuestra Señora de los Dolores Xaltocan, de 1751 y la capilla de Belem, de 1758.

Es precisamente durante la época colonial que se originan importantes celebraciones religiosas que en la actualidad se siguen realizando con gran colorido y solemnidad. ${ }^{27}$ Tal es el caso de la Fiesta de Xaltocan o Nuestra Señora de los Dolores, cuya leyenda de aparición se remonta a 1700. Comprende 15 días consecutivos (9-24 de febrero) dos domingos antes del miércoles de ceniza; misas, cohetes, ruedas pirotécnicas, voladores de Papantla y comida típica, son algunos de los eventos que la componen.

Importante también es la Fiesta del Niño Pa o Niño Pan (el niño del lugar); imagen milagrosa de un niño dios que se venera desde hace más de 400 años y que desde el siglo XIX peregrina por los hogares de Xochimilco. Dada su importancia en la sociedad xochimilca se ha creado una mayordomía especial para custodiarlo, misma que comienza habitualmente el 2 de febrero. Ese día el anfitrión lo recibe de manos de las autoridades eclesiásticas en medio de una procesión acompañada con música, cohetes y flores. El mayordomo se compromete a rezar un rosario todos los días, a 1levar a cabo una misa mensual y a celebrar las fiestas de Navidad, Reyes y Candelaria. Pero las fiestas más importantes son las posadas, pues el "Niño Pan" las preside desde antes de nacer simbólicamente.

La Feria de la "alegría y el olivo", en honor al dulce de la "alegría". Este dulce se originó cuando los franciscanos, uniendo la semilla del "amaranto" con miel, descubrieron que dicha unión tenía un sabor muy agradable, dando al dulce resultante el nombre de "alegría". En honor a este

27 Para una descripción de estas fiestas, vid. Farías, op. cit., pp. 132-136. 
28 Viajeros extranjeros dejaron testimonio de este paisaje en sus castas y otros escritos, como fue el caso en 1841 de Madame Calderón de la Barca. La vida en México. México, Porrúa, 1967 y el de la condesa Paula Kolintz en sus cartas, vid. Un viaje a México en 1864. México, FCE, 1984, pp. 119-120. tradicional dulce mexicano se celebra esta feria entre el 2 y el 23 de febrero en el pueblo de Santiago Tulyehualco. En esos días hay eventos artísticos, puestos de antojitos mexicanos, alegrías, olivos, pan, etc.

Otras celebraciones son: La fiesta del santo patrón de Xochimilco, las procesiones en Semana Santa, el día de la Santa Cruz (2 de mayo), el día de los fieles difuntos (2 de noviembre), el día de la Virgen de Guadalupe (12 de diciembre), las fiestas de los santos patrones de barrios y pueblos, etc.

De igual manera, cerca de Xochimilco, en el antiguo canal de Santa Anita, el virrey Conde de Revillagigedo estableció una fiesta típica actualmente conocida como "La Flor más Bella del Ejido" En la actualidad se realiza precisamente en la delegación Xochimilco. Se verifica durante los 15 días anteriores a la Semana Santa; justamente el viernes de Dolores se corona a la triunfadora del certamen, que se elige entre las señoritas participantes de las delegaciones que aún conservan ejidos vistiendo trajes típicos del Valle de México. Junto con el certamen de belleza hay otros de canoas alegóricas, floricultura, gastronomía, etc.

En suma, podemos decir que la aculturación Xochimilca no fue una asimilación completa a las formas culturales españolas, sino una adaptación cuidadosa, preservando muchos aspectos del Xochimilco prehispánico, dentro del mismo ambiente de la colonia.

\section{XOCHIMILCO DURANTE EL SIGLO XIX}

Durante los dos primeros tercios del siglo XIX Xochimilco conservó muchas de las características económicas, sociales y culturales de la época colonial. Se mantuvo la producción en chinampas. Xochimilco continuó mandando cientos de canoas anualmente a la ciudad de México cargadas de tomates, chiles, calabazas, productos de la tierra caliente, frutas y flores.

Desde los lagos de Chalco y Xochimilco, pasando por el canal de Santa Anita hasta el canal de la Viga en el que se veía desfilar canoas en un constante ir y venir hasta concluir un recorrido en el célebre muelle de Roldán en la Merced. ${ }^{28}$ 
En términos demográficos y socioeconómicos la población se mantuvo estable. ${ }^{29}$ El sector indígena era el mayoritario. Una buena parte eran campesinos chinamperos, la otra junto con mestizos y los descendientes de españoles continuó en la ciudad y barrios desempeñando el comercio, la producción de canoas y trajineras, la de manufacturas tradicionales y actividades ganaderas y agrícolas en haciendas y ranchos. No hay señales de que hubiera una continuidad respecto a la producción textilera en obrajes reportada en el siglo XVII.

La configuración de los barrios, pueblos, y el centro se mantuvo casi igual. Únicamente se crearon cuatro nuevos barrios: San Esteban, San Lorenzo, San Diego y las Ánimas o Guadalupita. Se delimitó el centro con la inclusión de la Iglesia de San Bernardino de Siena, el mercado, los jardines Juárez, Morelos e Hidalgo, la alcaldía, el registro civil, la policía, tiendas, un mercado cubierto y algunas fondas. Alrededor de este núcleo y en trazos rectos estaba dispuesta la ciudad que contaba de unas cuantas calles a las que seguían los barrios. Por su parte, los pueblos también cambiaron algo en cuanto a sus limites. ${ }^{30}$ Y se mantuvieron los ranchos y haciendas agropecuarias.

Las luchas entre liberales y conservadores parecen no haber afectado la vida de Xochimilco; ni aun los primeros barcos de vapor (realizaban viajes promocionales y para el público) que a partir de 1850 se veían pasar a lo lejos en su ruta de la Viga a Chalco, pasando por Mexicalzingo y otros sitios. ${ }^{31}$

Fue a partir del triunfo juarista liberal sobre Maximiliano en 1867 y sobre todo a finales del porfiriato que los habitantes de Xochimilco comenzaron a observar y resentir los embates de la modernidad y los del crecimiento de la ciudad de México. Es el momento en el que se comenzó a modificar la urbanización y el medio ambiente de la ciudad de Xochimilco.

Varios de los prefectos y presidentes municipales que gobernaron Xochimilco realizaron obras públicas importantes. Se implantó la educación primaria popular en 1871 y se edificó el Palacio Municipal (1869-1871), ocupando la parte poniente del jardín Hidalgo.

A finales del porfiriato los habitantes de Xochimilco comienzan a recibir servicios modernos tales como el de
29 Es casi seguro que el número de habitaciones haya sido alrededor de 11 000.

30 Peralta Flores y Rojas Ramírez, op. cit., pp. 4647.

31 Carlos J. Sierra, Breve historia de la Navegación en la Ciudad de México, 3a. ed. México, Departamento del Distrito Federal, 1973, pp. 55-60. 
32 Hacia 1905 se impulsó la construcción de la vía de tranvías, una Cía. Privada estableció la ruta HuipulcoTulyehualco; también las del llamado ferrocarril de circunvalación, que acarrearía los materiales destinados ala construcción del acueducto de Xochimilco. En el mismo año la Dirección General de Obras Públicas celebró contratos con particulares para el encendido de lámparas de petróleo en la cabecera y algunos pueblos. Vid. Peralta Flores y Rojas Ramírez, op. cit., pp. 39-41.

33 Ibidem, pp. 39-40.

34 Antonio García Cubas, Diccionario geográfico, histórico y biográfico de los Estados Unidos Mexicanos. 5 vols. México, Oficina Tipográfica de la Secretaría de Fomento, 1891, v. 5, p. 451.

35 José Rogelio Álvarez, coord. gral., Imagen de la gran capital. México, Enciclopedia de México, 1985, p. 313. tranvías, alumbrado y agua entubada, ${ }^{32}$ pero también una parte de pobladores comienza a perder sus costumbres y tradiciones.

De mayor trascendencia para la producción chinampera fue la puesta en marcha de los proyectos para abastecer de agua a la cada vez más grande ciudad de México. Hacia 1900 el presidente Porfirio Díaz giró órdenes para dotar de agua potable a los habitantes de las recién creadas colonias como la Guerrero, Chopo, Juárez, Roma, Condesa, Romero Rubio y Santa María la Ribera. Para tal efecto se comenzó a bombear el agua de los manantiales más grandes en profundidad y diámetro que alimentaban los canales, conduciéndola hasta la estación Condesa y de ahí hasta los tanques de Dolores. ${ }^{33}$

La construcción del acueducto hizo que los manantiales, al interrumpirse su libre cause hacia los canales y el lago, provocaran el estancamiento de las aguas y una baja considerable en el nivel freático con su consecuente contaminación y repercusión en los cultivos chinamperos.

Durante la época se manifiesta un ligero aumento de la población en la jurisdicción. Según el Diccionario de García Cubas, en 1890 Xochimilco era una prefectura del Distrito Federal que contaba con 12652 habitantes distribuidos en la ciudad de Xochimilco, pueblos de Tepepan, Xochitepec, Santiago Tecalpatlapa, Xicalco, San Francisco Tlalnepantla, San Mateo Xalpa, San Salvador Anauhtempa, Santa Cecilia Yancuitlalpan, San Andrés Almayuca, San Lucas Xochimanca, San Gregorio Atlapulco, Nativitas, Santa Cruz Acapixcan y San Lorenzo Atemoya; hacienda de Olmedo y rancho de la Noria, Rivera, San Ignacio, Tepejoyuca, Luciantla, Coatelán y Xaltocan. ${ }^{34}$

En vísperas de la Revolución Mexicana de 1910, la municipalidad de Xochimilco tenía 26000 habitantes, incluyendo la cabecera (10 710) y varios pueblos que en la actualidad pertenecen a otras delegaciones. ${ }^{35}$

Durante la mayor parte de esta época los habitantes de Xochimilco mantuvieron sus actividades tradicionales, sin embargo, a finales una parte (sobre todo aquella que resentía la baja del nivel del agua en sus chinampas) fue encontrando trabajo en las obras del tendido de las vías férreas y en otras que la jurisdicción fue requiriendo o en otros sitios fuera de Xochimilco. 
Durante el porfiriato se le dio un nuevo impulso a la fiesta de la "Flor más bella del Ejido"; esta fiesta se seguía realizando en Santa Anita, pero a partir de 1897 se le 11amó "Viernes de Primavera". Además, circularon por sus canales, aparte de las canoas y trajineras típicas, canoas de vela, de remos largos y de vapor. Se establecieron dos vapores entre Xochimilco y la garita de Ixtacalco por Mexicaltzingo; el recorrido se hacía en dos horas y salían tres veces por día en ambos sentidos. ${ }^{36}$

\section{XOCHIMILCO DURANTE EL SIGLO XX}

a) La lucha armada 1910-1920

Durante la lucha armada revolucionaria la región de Xochimilco estuvo dominada en gran medida, por los zapatistas. En el centro de la ciudad lacustre tuvo el encuentro histórico de los generales Emiliano Zapata y Francisco Villa (diciembre de 1914); encuentro conocido como "Pacto de Xochimilco".

En 1915 Venustiano Carranza publicó el decreto que restituye en el Distrito Federal los ayuntamientos, desde entonces y hasta 1929 Xochimilco se constituyó como uno de los 14 municipios que formaron el Distrito Federal y fue gobernado por un presidente municipal electo cada dos años.

Durante los enfrentamientos revolucionarios gran parte de la población se escondió en las chinampas más lejanas del centro de Xochimilco, otro tanto se fue a lugares más lejanos. Los principales edificios públicos (escuelas, portales del mercado y palacio municipal) se convirtieron en cuarteles. ${ }^{37}$ Como resultado inmediato de la proclamación de la Constitución de 1917, en el año 1919 se repartieron a campesinos tierras de Tepepan, San Gregorio y Tulyehualco, así como algunas porciones que estaban pendientes en las ciénegas. ${ }^{38}$ También en Nativitas se construyeron los primeros embarcaderos, se reforestó el bosque, se fundó un vivero de árboles y se edificó el jardín de aguas potables.

$36 \mathrm{Ibidem}$.

37 Peralta Flores y Rojas

Ramírez, op. cit., p. 41. 38 Farías, op. cit., p. 140. 
39 Jiménez-Osorio, op. cit., p. 3. 40 Peralta Flores y Rojas Ramírez, op. cit., p. 50. 41 Álvarez, op. cit., p. 310. b) El periodo 1920-1950

Durante las siguientes tres décadas, la producción agrícola en chinampas continuó siendo impactada al seguirse bombeando, en mayores cantidades, el agua de los manantiales de la región, de tal manera que en los años de las décadas de 1940 y 1950 dejaron de alimentar a los canales y lagunas. Las chinampas de Tulyehualco, Acalpixcan y Nativitas casi desaparecieron, y las de Xochimilco, San Luis San Gregorio y Tláhuac se redujeron drásticamente. ${ }^{39}$

A causa de la desecación parcial del lago se formaron inmensos pantanos en los terrenos ribereños. En los canales próximos a la población se introdujeron, como plantas de ornato, lirios que con el tiempo se convirtieron en plaga.

Ante esta situación, un buen número de habitantes de la ahora delegación de Xochimilco emigró temporalmente a la ciudad de México y otros sitios para sumarse a la fuerza de trabajo en la construcción, jardinería otros oficios que el crecimiento de la misma requería. Otra permaneció en Xochimilco desempeñando actividades tradicionales.

Sin embargo, al quedar mejor comunicada con el centro de la ciudad, la delegación, por las facilidades que se presentaron para adquirir terrenos para la construcción de casas-habitación y otro tipo de establecimientos, y por la mejora de servicios públicos de que estaba siendo objeto, atrajo nuevos residentes y actividades económicas.

Efectivamente en los años cuarenta surge una zona industrial localizada entre el centro de Xochimilco y Tepepan, compuesta por una fábrica de hilados y tejidos de lana, un laboratorio de productos farmacéuticos, una fábrica de hilados y tejidos de algodón y una fábrica de zapatos, entre otros establecimientos. Esta industria contrató una parte de la población de Xochimilco. ${ }^{40}$

Después de haber sufrido una ligera baja a consecuencia de la Revolución, la población de la delegación pasó de 22000 (9 000 en la cabecera) habitantes en 1930 a más de 43000 veinte años después (1950), de los cuales 15000 aproximadamente estaban en la cabecera. ${ }^{41}$

En aquellas áreas donde los canales todavía tenían agua, se siguió cultivando, y en la cabecera se mantenía la producción de artesanías y el ambiente provinciano que la había caracterizado. Con sus monumentos colo- 
niales, sus mercados y paseos en trajineras, Xochimilco aún era pintoresco. E1 27 de septiembre de 1934 el presidente Abelardo Rodríguez firmó un decreto en el que se declaró a Xochimilco (templo, convento, barrios, chinampas y canales) como "Zona Típica Pintoresca", junto con las delegaciones Villa Álvaro Obregón y Coyoacán.

Es entonces cuando las autoridades procuraron mejorar los servicios públicos. Para 1936 se efectuaron modificaciones urbanas al centro de Xochimilco. Se crearon varias avenidas anchas y se ampliaron otras, procurando conservar los bellos paisajes de Xochimilco. En 1909 se había inaugurado ya el primer alumbrado público del centro de Xochimilco. En los años siguientes se extendió a los pueblos cercanos, de tal manera que para 1950 ya 1legaba a San Lucas, San Mateo, Nativitas, Santa Cruz, Tulyehualco, Tepepan y Xochitepec.

Por otra parte, se construyó el drenaje de Xochimilco. En su primera etapa (1937 a 1940) se inició de una forma más efectiva el surtimiento de agua potable. Asimismo, al servicio de tranvías eléctricos hasta Xochimilco y Tulyehualco que se había instalado en 1909, se sumó, en 1929 el de autobuses que cubría la línea México-Xochimilco; para 1940 la línea cubría el servicio hasta otros pueblos. $^{42}$

También se 1levaron a cabo mejoras en los edificios públicos. En 1951 se demolió el antiguo palacio de gobierno para dar paso a la construcción de uno nuevo, mismo que al año siguiente inauguró el presidente Miguel Alemán. Este edificio estuvo funcionando hasta 1972 cuando fue demolido para construir otro.

También son de esta época la construcción de varios restaurantes de comida típica y la de trece escuelas primarias: una de alfabetización, una de pintura al aire libre y una rural. ${ }^{43}$

C) De 1950 a la década de 1990

Desde fines de la década de los cincuenta hasta la década de los noventa, Xochimilco ha sufrido más cambios, esta vez de una forma drástica y acelerada. Por un lado continuó el proceso de desecación de los canales al con-
42 Farias, op. cit., pp. 142-149.

43 Peralta Flores y Rojas

Ramírez, op. cit., p. 49. 
44 Jiménez Osorio, op. cit., pp. 144-149.

45 Ibidem, p. 8.

46 Ibidem, p. 9. tinuarse explotando irracionalmente los recursos hidráulicos de la región. Hasta mediados de los años ochenta existían 213 pozos en la zona Xochimilco-Tláhuac, de los cuales extraían 7700 litros por segundo, lo que representa el doble de lo que logra recargarse naturalmente el

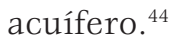

Esta situación provocó necesariamente una disminución de la diversidad de la fauna y de la flora, mayor presencia de plagas y enfermedades en los cultivos, reducción de la superficie cultivada y cultivable (desde mediados de los años cuarenta a mediados de los ochenta se han perdido el $80 \%$ de los espacios agrícolas y en los últimos 20 años de ese periodo disminuyó en un $42 \%$ ) y con ello baja en la producción y pérdida de autosuficiencia alimentaria. ${ }^{45}$

Cabe recordar que hasta fines de los ochenta el área de chinampas era de 2293 hectáreas, las cuales conservaron su potencial productivo, pero únicamente en 1070 hectáreas se realizan actividades agropecuarias. Son seis los poblados que conforman la actual zona chinampera: Xochimilco, San Gregorio, San Luis Tlaxialtemalco, Tláhuac, Mixquic y Tetelco.

El tamaño de las chinampas oscila entre 0.25 ha. y 1.5 ha. Básicamente existen tres procesos productivos importantes en la región chinampera, a saber: el maíz, las hortalizas y las flores. Las dos últimas son los productos más importantes. Las hortalizas ocupan e1 70\% del total de esta área y se producen principalmente en San Gregorio y Mixquic, mientras que las flores se cultivan principalmente en San Luis y el maíz en Xochimilco y Tetelco. ${ }^{46} \mathrm{La}$ ganadería ha existido como una actividad complementaria en estos poblados.

Por otro lado, al irse secando la zona chinampera, sus terrenos poco a poco fueron cambiando de uso, pues los chinamperos al no tener otras opciones para hacer productiva la tierra ya que al ser el área chinampera propiedad familiar y al carecer los propietarios de títulos públicos de la propiedad, están limitados para el financiamiento (por no ser sujetos de crédito) al parecer optaron por venderla. Con ello muchas hectáreas de cultivo fueron destinadas para uso habitacional, industrial, comercial y de servicios públicos; sobre todo a partir de los años 
setenta cuando la delegación Xochimilco inicia de una forma definitiva su integración a la zona urbana del Dis47 Farías, op. cit., pp. 144-149. 48 Alvarez, op. cit., p. 310 trito Federal al construirse obras viales como la carretera México-Xochimilco-Tulyehualco, la prolongación de la Av. División del Norte, y el Anillo Periférico, la Calzada de Tlalpan, la del Hueso y las avenidas Nativitas y Canal de Miramontes; y ampliarse y mejorarse los servicios de transporte público que llegaron hasta Xochimilco. En 1956 se reestructuró el sistema de trenes eléctricos, se inauguraron nuevas rutas, se contó con nuevas unidades y se brindó servicio "rápido". En 1976 se sustituyeron los 17 tranvías viejos que entraban a Xochimilco por unidades de color amarillo naranja (trenes restaurados y en buenas condiciones), asimismo aumentó y mejoró el servicio de autobuses, ya en la década de los setenta funcionaban servicios de "rápidos", autobuses denominados "Delfines", "Ballenas" y los "Metrobuses". ${ }^{47}$

Actualmente la ordenación del espacio urbano se ha visto afectada en casi todos los pueblos y barrios de Xochimilco. Hoy en día la estructura territorial de la delegación es de tipo suburbana y rural.

Con estos cambios, y la cierta facilidad que ha habido para adquirir terrenos y establecerse en la región, la población de la delegación aumentó increíblemente, ya que a mediados de la década de los ochenta tenía una población de 369000 habitantes, ${ }^{48}$ de los cuales representaban la población nativa 50000 personas. Evidentemente que por representar un área propicia para la comercialización del suelo y la construcción de viviendas, bien comunicada con el resto del Distrito Federal, se ha visto invadida por cientos de miles de personas provenientes de otras partes del D.F. y del interior del país.

Se ha estimado que del total de habitantes señalado, 333000 viven en el medio urbano, (aproximadamente más de 20000 nativos) y 26000 (población nativa) en el rural. Esta población vive en una superficie de $122 \mathrm{~km}^{2}$., de los cuales 11 corresponden al área urbana tradicional, es decir, la cabecera y 17 barrios; 30 al antiguo vaso del lago y 86 a la parte montañosa. A estas últimas partes pertenecen los 15 pueblos tradicionales mencionados con anterioridad, donde se han formado 76 colonias, con lo 
49 Ibidem.

50 Ibidem.

51 Farías, op. cit., pp. 142-144. cual ha aumentado considerablemente el área urbana y suburbana de la delegación, de tal modo que en la actualidad se puede decir que es predominantemente urbana. En las últimas décadas se han multiplicado los fraccionamientos residenciales y las habitaciones de tipo departamental, de tal modo que este tipo de construcción ocupa en la actualidad el 65\% del suelo. De igual modo, ahora las industrias establecidas ocupan el 15\% y el comercio y los servicios el $20 \% .^{49}$

En particular los servicios públicos que han proliferado hasta mediados de la década de los ochenta, son: 17 jardines de niños, 51 primarias, 14 secundarias, 2 escuelas de enseñanza media superior, una normal y varias escuelas de la UNAM y el IPN. Asimismo la delegación cuenta con una clínica del Issste, dos centros de salud y un hospital regional; ocho centros culturales, un museo y 19 instalaciones deportivas, entre ellas el canal de Cuemanco para competencia de remo y canotaje, y el Centro Deportivo Xochimilco. ${ }^{50}$ Aunado a lo anterior, en los 1980 se inauguró el edificio delegacional. Cuenta con 15 panteones. A partir de 1971 comenzó a funcionar la luz mercurial; en 1980 se instalaron los primeros faroles y tubos de luz de vapor de sodio. Para 1980 se habían tendido ya $80 \mathrm{kms}$. de drenaje y continuado los trabajos de alcantarillado pluvial. Simultáneamente a estos trabajos se continuaron las obras para surtir de agua potable a la población de la cabecera. Estos beneficios se han ido extendiendo paulatinamente a los pueblos de la delegación. Hacia 1980 Tulyehualco, Tepepan y Tepalcatlalpan contaban con drenaje y una red completa de agua potable. ${ }^{51}$

Resulta comprensible como gran parte de la población nativa de la cabecera, barrios y pueblos, al verse afectada en su producción agrícola alcanzada y cada vez más rodeada por la mancha urbana, se haya visto obligada a abandonar sus actividades tradicionales para integrarse como fuerza de trabajo en la industria, servicios, comercio, construcción, jardinería y servicio doméstico de la propia región de Xochimilco y de otras áreas del D.F.; otra parte continúa con sus actividades tradicionales, de esta última, la que se dedica a la producción agrícola se ha visto cada vez más reducida, al igual que sus chinampas. 
En esta época el esfuerzo de los trabajadores nativos de Xochimilco, la delegación, el Departamento del Distrito Federal y otras instancias tanto públicas como privadas, han hecho posible la restitución de una parte del volúmen de agua extraído de los manantiales por medio de la alimentación artificial de los canales con agua tratada y residual. ${ }^{52}$ Estos trabajos se vieron reforzados cuando en diciembre de 1987 se declaró a Xochimilco como "Patrimonio Cultural de la Humanidad" y en 1990, cuando las autoridades, conscientes de la importancia del área chinampera por su actividad productiva (agricultura y turismo), como reserva ecológica fundamental para mejorar el medio ambiente de la gran ciudad de México y como patrimonio histórico cultural, emprendieron la rehabilitación integral de la región chinampera por medio de la puesta en marcha del "Plan de rescate ecológico de Xochimilco". Es entonces que el presidente Carlos Salinas de Gortari firma el decreto de expropiación y la declaratoria de área natural protegida de la zona chinampera.

Estas acciones han hecho posible que a la fecha Xochimilco cuente con 3000 hectáreas protegidas; 200 kms. de canales que han vuelto a ser navegables; 1200 hectáreas de chinampería sembrada de nuevo (que junto con las 1070 que se cultivaron suman 2 270) mejor drenaje; dos nuevas plantas de tratamiento de agua; un nuevo lago cuyas dimensiones son 25 veces más grandes que el de Chapultepec; cuatro lagunas de regulación para evitar inundaciones: 170 especies vegetales recuperadas y 120 especies de aves que han regresado a la zona. Aunado a lo anterior, se cuenta con un nuevo mercado de flores (el más grande del continente); invernaderos para la producción de hortalizas y flores; 4000 nuevos árboles plantados; un centro de acopio para empacar 100 toneladas de legumbres por día y nuevas áreas deportivas. ${ }^{53}$

Si bien es cierto que una parte de la población nativa de Xochimilco se ha beneficiado con las obras 1levadas a cabo, aún hacen falta más acciones de ese tipo para hacer que la agricultura vuelva a representar una buena opción de ingresos para las personas que tienen chinampas, así como ya lo representa el comercio, el turismo, las artesanías, la producción de plantas y árboles a las personas que a ello se dedican.
52 En 1957 el Departamento del Distrito Federal decidió restituir parte del volumen de agua extraída de los manantiales con la alimentación artificial de los canales, primero con los ríos de Churubusco y San Buenaventura, por el cauce abierto del Canal Nacional, y en 1959, con aguas tratadas de la Planta de Aculco, Coyoacán. En 1971, la nueva planta del Cerro de la Estrella aportó agua residual a los canales de la región. Vid. Jiménez, op. cit., p. 3.

53 En Uno mas Uno, sección Valle de México, año XVI, núm. 5 606. México, 6 de junio, 1993, p. 11; en Excélsior, sección Metropolitana, año LXVII, t. III, núm. 27 729. México 6 de junio, 1993, p. 5. 
Ahora el visitante puede observar las chinampas que son, sin lugar a dudas, el último testimonio vivo de una forma de producción que alimentó e hizo prosperar a vastos grupos humanos en los periodos prehispánicos, colonial y republicano; y como los pobladores originarios continúan organizando algunas prácticas productivas y sociales que aún lo distinguen y que permiten hablar de la persistencia de costumbres cotidianas en los pueblos chinamperos. Las chinampas significan para los habitantes locales parte de sus creencias, costumbres, relaciones sociales, etc. que los diferencian. Esto es lo que ha permitido que las chinampas se conserven y que en esta segunda mitad del siglo se estén recuperando.

Recorrer la zona chinampera por los canales y lagunas destinadas al turismo, resulta una experiencia muy agradable y reconfortante, ya que significa cambiar el ritmo y ambiente de la ciudad por los que nos imprime el ir admirando la incomparable belleza natural y ecológica de la zona. Entre otros canales importantes podemos mencionar el de Apatlaco y el de Canal Nacional; y lagunas tales como el Toro, La Virgen, Tlilac, etc. El Canal de Cuemanco es conocido internacionalmente por haberse celebrado ahí las competencias de remos y canotaje durante los XIX Juegos Olímpicos, México 1968.

El recorrido por la región lacustre nos permite conocer los embarcaderos y mercados de artesanías, como los de Nuevo Nativitas y Cuemanco. Otros embarcaderos son: Caltongo, Nativitas Zacapa, Fernando Celada, Belem, Salitre y San Cristóbal.

Con respecto a los mercados, precisamente uno de los atractivos de Xochimilco es su céntrico mercado donde se puede adquirir verdura fresca, comida hecha, plantas de ornato, etc. En particular, para adquirir una gran variedad de flores, árboles frutales, plantas, tierra negra y de hoja, macetas de diferentes figuras y materiales, maceteros y muchos otros objetos para decoración de jardines, es imprescindible visitar alguno de sus múltiples viveros, como lo es el denominado Madreselva o el de Cuemanco.

Aunado a los atractivos descritos, Xochimilco también cuenta con áreas boscosas, un ejemplo de esto son los bosques de San Luis Tlaxialtemalco y el de Nativitas. 
Por su rica historia, sus chinampas, arte colonial, fiestas, tradiciones y ambiente ecológico, Xochimilco es hoy en día uno de los sitios más atractivos e interesantes de la ciudad de México que todo visitante, nacional y extranjero está obligado a visitar. 
